Counsellia: Jurnal Bimbingan dan Konseling 8 (1), 27 - 36 | Mei 2018

Copyright 02017 Universitas PGRI Madiun

ISSN: 2088-3072 (Print) / 2477-5886 (Online)

Available online at: http://e-journal.unipma.ac.id/index.php/JBK

DOI: 10.25273/counsellia.v8i1.2306

\title{
Pengaruh Peer Group Support dan Resillience terhadap Kemampuan Coping Adaptif Siswa SMA
}

\author{
Yunia Widi Astuti ${ }^{1}$; Noviyanti Kartika Dewi ${ }^{2}$; Vitalis Djarot Sumarwoto ${ }^{3}$ \\ ${ }^{1}$ FKIP, Universitas Negeri Madiun \\ nwidi83@gmail.com \\ ${ }^{2}$ FKIP, Universitas Negeri Madiun \\ noviyantibk411@gmail.com \\ ${ }^{3}$ FKIP, Universitas Negeri Madiun \\ vitalisdjarot@yahoo.com
}

\begin{abstract}
Abstrak
Kemampuan coping adaptif sangat penting dimiliki oleh remaja. Kemampuan coping adaptif membantu remaja untuk bisa memecahkan masalah yang dihadapi dalam menyelesaikan tugas-tugas perkembangannya. Selain itu resiliensi juga memiliki peran yang penting dalam kehidupan remaja yaitu sebagai kemampuan ketahanan diri saat remaja berada pada situasi yang mendesak. Keberhasilan siswa dalam mengatsi masalahnya tidak lepas dari peran penting peer grooup support atau tidak lepas dari dukungan teman sebayanya.

Penelitian ini bertujuan untuk mengetahui pengaruh peer group support dan resilience terhadap kemampuan coping adaptif siswa Sekolah Menengah Atas (SMA). Sampel penelitian adalah siswa kelas SMA, yang berjumlah 100 siswa. Teknik penetapan sampel menggunakan teknik sampling jenuh. Pengumpulan data menggunakan instrumen skala psikologis, untuk mengungkap data tentang peer group support, resilience, dan kemampuan coping adaptif.

Berdasarkan hasil analisis data: (1) pengaruh peer group support terhadap kemampuan coping adaptif; dan (2) pengaruh resilience terhadap kemampuan coping adaptif dianalisis dengan rumus korelasi product moment. Sedangkan (c) pengaruh peer group support dan resilience terhadap kemampuan coping adaptif dianalisis dengan rumus bangun regresi: dua prediktor. Hasil penelitian menunjukan: Ada pengaruh secara signifikan peer group support dan resilience terhadap kemampuan coping adaptif siswa SMA.
\end{abstract}

Kata Kunci : Peer Group Support, Resilience dan Kemampuan Coping Adaptif

\begin{abstract}
The ability of adaptive coping is very important for teens. Adaptive coping skills help teenagers to solve the problems they face in completing their developmental tasks. In addition, resilience also has an important role in adolescence as a self-defense ability when teenagers are in an urgent situation. The success of students in mengatsi problem can not be separated from the important role of peer grooup support or can not be separated from the support of peers.
\end{abstract}


This study aims to determine the effect of peer group support and resilience on the ability of adaptive coping of high school students (SMA). The sample of the research is high school students, which amounts to 100 students. Sample determination technique using saturated sampling technique. Data collection using psychological-scale instruments, to reveal data about peer group support, resilience, and adaptive coping skills.

Based on data analysis result: (1) peer group support effect on adaptive coping ability; and (2) the effect of resilience on adaptive coping ability is analyzed by product moment correlation formula. While (c) the effect of peer group support and resilience on adaptive coping ability was analyzed by regression build formula: two predictors. The results showed: There is a significant influence peer group support and resilience to the ability of adaptive coping of high school students.

Keywords: Peer Group Support, Resilience and Adaptive Coping Capabilities

\section{PENDAHULUAN}

Remaja memiliki karakteristik yang khas dibandingan dengan periode-periode pada perkembangan lainnya. Pada masa ini, remaja mengalami perkembangan fisik dan psikologis yang cepat dan penting. Sejalan dengan perubahan-perubahan yang ada dalam dirinya, remaja juga dihadapkan pada tugas-tugas perkembangan yang harus dipenuhi. Tugas perkembangan ini berbeda dari tugas pada masa kanak-kanak. Apabila tugas-tugas tersebut berhasil diselesaikan dengan baik maka akan tercapai kepuasan, kebahagiaan dan penerimaan dari lingkungan namun jika tidak berhasil menyelesaikan tugas-tugas tersebut maka remaja akan mengalami kesedihan, kecemasan, kesepian dan lain-lain.

Seiring dengan perkembangan pesat yang dialami remaja terkait fisik dan psikisnya, remaja juga mengalami berbagai hambatan dan masalah dalam kehidupannya. Masa remaja sering dianggap sebagai periode kerentanan karena sebagian besar remaja sering mengambil bagian dalam perilaku yang berisiko. Banyaknya permasalahan dan krisis yang terjadi pada masa remaja ini menjadikan banyak ahli dalam bidang psikologi perkembangan menyebutnya sebagai masa krisis.

Remaja yang dimaksud dalam pembahasan ini adalah individu yang secara resmi terdaftar sebagai siswa di Sekolah Menengah Atas (SMA). Siswa dituntut untuk dapat aktif dan kreatif belajar di sekolah, yang realitanya tidak jarang siswa mendapat kesulitan dan permasalahan dalam menjalani proses belajar mengajar disekolah yang menyebabkan siswa tertekan. Kemampuan copping adaptif memberi petunjuk kepada siswa agar dapat menyelesaikan menyelsaikan 
masalah dan menyesuaikan diri secara tepat.

Pada dasarnya, setiap siswa memiliki daya-daya jiwa atau potensi yang dibawa sejak lahir, yang mewujud dalam aktivitas sehari-hari, baik di sekolah maupun di luar sekolah. Daya-daya jiwa ini perlu dikembangkan seoptimal mungkin untuk mendukung tujuan hidup dan dalam mencapai tujuan pendidikan dan pembelajaran. Daya jiwa yang perlu dikembangkan siswa berkaitan erat dengan kemampuan coping adaptif.

Coping adalah proses pemikiran dan perilaku yang digunakan orang untuk mengelola tuntutan internal dan eksternal dari situasi yang mereka nilai sebagai stres. Menurut Saptoto (2010) kemampuan coping adaptif adalah kemampuan siswa dalam proses aktivitas kognitif yang disertai dengan aktifitas perilaku dalam pemilihan cara menyesuaikan diri secara tepat terhadap situasi hidup yang menekan, yang timbul dari hubungan individu dengan lingkungannya. Dengan demikian individu akan berusaha untuk mengelola, menguasai, mentolerir, mengurangi atau meminimalkan tuntutan lingkungan yang penuh tekanan.

Virginia Satir, seorang terapis klinis terkemuka berkata "Masalah bukanlah masalah, mengatasi adalah masalahnya." Pernyataan tersebut menggambarkan bahwa individu dapat menanggapi pengalaman stress baik dengan cara adaptif maupun maladaptif (Thomson, dkk. 2010). Keterampilan dalam coping adaptif dapat dipelajari dan ditingkatkan untuk mengurangi tekanan psikologis dan meningkatkan kesejahteraan (Bartram \& Dianne. 2008). Pengembangan kemampuan coping adatif ini dalam kehidupan seharihari siswa dipengaruhi oleh dua faktor pokok, yaitu faktor yang melekat pada diri siswa, dan faktor yang berasal luar diri siswa itu sendiri. Termasuk faktor yang melekat dalam diri siswa adalah resillience.

Lebih lanjut Wanarsih (2006) menjelaskan resillience sebagai kapasitas atau kemampuan untuk mentranformasi diri dengan cara yang positif. Resillience sering dilihat sebagai kualitas pribadi yang adaptif dan tahan terhadap tekanan yang memungkinkan individu untuk berkembang meskipun mengalami kesulitan. Faktor resilliencei dapat dimaknai sebagai daya pantul atau daya lenting untuk menangkal masalah dan kesulitan hidup siswa. Oleh sebab itu resillience dibutuhkan siswa agar mampu menanggulangi kesulitan hidup. Pernyataan ini memberi petunjuk bahwa semakin besar atau tinggi daya tangkal siswa terhadap masalah dan kesulitan hidup maka semakin mampu siswa mengadakan coping adaptif, yang pada akhirnya memperlancar siswa dalam mencapai tujuan. 
Kemampuan copping adaptif memberi petunjuk bahwa apabila dalam diri siswa SMA tersebut dalam hidupnya benar-benar menggunakan unsur kognitifnya dan disertai aktivitas yang mengarah kepada sikap positif, khususnya dalam memilih teknik untuk bergabung dengan lingkungannya dengan menyesuaikan diri secara tepat, maka siswa tersebut akan timbul sikap resiliencei yang positif. Sebaliknya, bila siswa mengembangkan sikap resiliencei yang baik niscaya dalam diri siswa tersebut telah memiliki modal untuk melakukan adaptasi dengan baik atau well adjusted (Winkel, 2007). Sebaliknya, jikalau dalam diri siswa justru akan timbul perilaku salah suai (maladjusted). Jadi jelas kedua faktor tersebut merupakan unsur yang saling mempengaruhi kehidupan siswa SMA. Faktor tersebut diperlukan ketika terjadi situasi yang menekan siswa yang ditimbulkan akibat hubungan dengan lingkungannya.

Faktor di luar diri siswa, yang dapat mempengaruhi kemampuan copping adaptif siswa adalah faktor yang berasal dari luar diri siswa, yang disebut dengan istilah peer group support atau yang lazim dinamakan bantuan kelompok sebaya. Bantuan yang berasal dari kelompok sebaya (tersebut antara lain meliputi rasa empati dan simpati terhadap sesama, rasa kesetiakawanan, dan toleransi terhadap lingkungan. Perlu diketahui bahwa dalam menumbuhkan sikap seperti diuraikan di atas tidaka senantiasa berjalan sebagaimana yang dicita-citakan. Dalam pertemanan di antara peer group support tidak dihindari akan ada konflik, dan konflik didalam pertemanan itu tidak bisa dihindari. Butuh sikap tertentu untuk bisa mengatasinya.

Usaha mengatasi sikap yang kurang menguntungkan bagi siswa dalam mengembangkan kemampuan coping adaptif adalah dengan cara banyak belajar dan menggali pengalaman hidup. Melalui semangat belajar tersebut maka siswa (SMA) lama kelamaan siswa yang tidak mampu mengatasi masalah menjadi memiliki kemampuan dan bahkan kesanggupan untuk mengatasi masalah yang menimpa siswa SMA tersebut. Lebih lanjut bagi siswa SMA yang merasakan stres dalam hidupnya harus mulai menghadapi dan menyesuaikan diri dengan stres yang dialami. Segala macam bentuk tuntutan baik secara eksternal maupun internal membutuhkan respon yang adaptif dari remaja. Ketika berhasil siswa dalam mengatsi masalah atau stressor mengakibatkan gangguan-gangguan psikologis yaitu perubahan fungsi tubuh, muncul reaksi maladatif, menjadi tidak bergairah, tidak bersemangat sehingga dapat mempengaruhi kesehatannya. 
Dengan memiliki teman sebaya maka siswa SMA banyak mendapat motivasi atau termotivasi oleh keadaan sekitarnya sehingga mampu menyelesaikan/bisa mengatasi tekanan yang dirasakannya tersebut. Tak dipungkiri lagi manusia sebagai mahluk sosial atau zooppoliticon yang tidak bisa hidup sendiri dan selalu membutuhkan bantuan orang lain. Karena itulah siswa SMA akan senantiasa mengadakan hubungan dengan sesamanya atau lembaga lain agar terjadi komunikasi yang bermanfaat bagi perkembangan hidupnya. Bantuan kelompok teman sebaya (peer group support) memiliki peran penting karena perkembangan pola pikir siswa dalam budaya Indonesia pada era sekarang telah berkembang pesat khususnya pada siswa SMA yang tumbuh menjadi negatif. Namun perkembangan yang pesat ini justru menimbulkan beberapa efek atau dampak negatif perkembangan siswa khususnya pada pola pikir dan perilaku siswa SMA itu sendiri.

Hubungan dengan teman sebaya memberi arti penting terhadap perkembangan kemampuan coping adaptif pada siswa. Karena saat siswa (SMA) beranjak dewasa akan lebih banyak berinteraksi dengan lingkungan teman sebayanya. Oleh sebab itu perlu disadari bahwa lingkungan teman sebaya dapat mempengaruhi perkembangan. Dampak pengfaruh tersebut dapat positif tetapi juga dapat negatif.
Meskipun demikian siswa (SMA) diperlukan sikap selektif dalam berkomunikasi dengan lingkungannya. Artinya dengan adanya resilience sesorang akan dapat terbantu mengatasi kesulitankesulitan hidup". Hubungan teman sebaya juga memberikan arti penting terhadap resilliensi individu. Membangun resilience siswa di sekolah dengan memperkuat hubungan-hubungan, yang mengarah pada peningkatan

Betolak dari uraian tersebut di atas maka peneliti merasa perlu mengkaji permasalahan ini secara lebih mendalam sehingga diharapkan akan diperoleh hasil yang akurat. Oleh karena itu dalam penelitian ini dikemukakan judul penelitian sebagai berikut: "Pengaruh Peer Group Support dan Resilience terhadap Kemampuan Copping Adaptif'

\section{METODE PENELITIAN}

Desain penelitian menggunakan korelasional eks postfacto, yang menurut Kelinger (dalam Sangaji dan Sopiah, 2010) adalah penelitian dimana variabel-variabel bebas telah terjadi ketika peneliti mulai dengan pengamatan variabel terikat. Hakikat penelitian ex post-facto terletak pada adanya keterikatan antar variabel bebas maupun antara variabel bebas dengan variabel terikat sudah terjadi sebelumnya secara alami. 
Bertolak dari uraian di atas, maka desain penelitian dapat dikemukakan sebagai berikut:

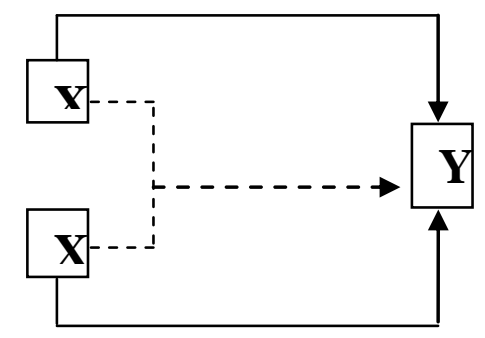

Gambar 1. Desain Korelasional Ex post-facto

Keterangan :

$\mathrm{X}_{1}$ : Peer group support ( Variabel bebas)

$\mathrm{X}_{2}$ : Resilience ( Variabel bebas)

$\mathrm{Y}$ : Kemampuan coping adaptif (Variabel Terikat)

Penelitian dilaksanakan di SMA Negeri 1 Kabupaten Ngawi pada tahun pelajaran 2017-2018, yang beralamat di di Jalan. Achmad Yani No 45 Ngawi, Kabupaten Ngawi. Populasi penelitian adalah semua siswa kelas X SMA Negeri 1 Ngawi tahun pelajaran 2017-2018, yang berjumlah 100 orang siswa. Sampel penelitian ditetapkan semua anggota populasi. Dengan demikian samapel penelitian ditetapkan dengan teknik sampling jenuh, mengingat semua anggota populasi digunakan sebagai anggota sampel penelitian dan bermaksud membuat generalisasi (Sugiyono, 2015).

Pengumpulan data penelitian menggunakan teknik angket, yaitu angket langsung dan tertutup. Analisis data penelitian menggunakan teknik statistik dengan rumus bangun Analisis Regresi: Dua Prediktor.

\section{HASIL PENELITIAN \\ Deskripsi data}

Deskripsi data skor hasil angket peer group support $\left(\mathrm{X}_{1}\right)$ diperoleh perhitungan sebagai berikut: $\mathrm{N}=$ 100, Rentang Skor angket: $20-80$, Mean $=63,43$, Median $=64$, Modus $=63$, Standard Devias $(\mathrm{SD})=5,734$, Skor tertinggi $=77$, dan, skor terendah $=43$. Mengingat data tersebut dilaporkan dengan grafik batang, maka perlu menghitung range (R) dan lebar kelas (i). Range (R) adalah selisih antara batas atas nyata skor tertinggi dan batas bawah nyata skor terendah $=76,5-42,5=$ 34. Ditentukan lebar kelas (i) $=5$, maka $\mathrm{R}$ dalam distribusi frekuensi bergolong $=(33+1): 5=7$.

Tabel 1. Distribusi Frekuensi Peer Group Support $\left(\mathrm{X}_{1}\right)$

\begin{tabular}{|c|c|c|}
\hline Interval & Frekuensi (f) & Persentase \\
\hline $65-79$ & 46 & $46 \%$ \\
\hline $50-64$ & 53 & $53 \%$ \\
\hline $35-49$ & 1 & $1 \%$ \\
\hline $20-34$ & 0 & $0 \%$ \\
\hline Jumlah & 100 & $100 \%$ \\
\hline
\end{tabular}

Bentuk grafik batang untuk distribusi frekuensi peer group support adalah sebagai berikut: 


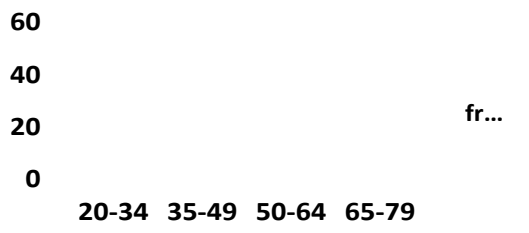

20-34 35-49 50-64 65-79

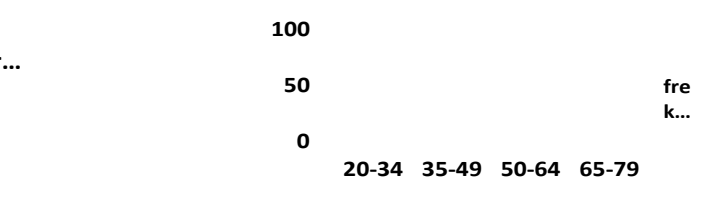

Gambar 2. Skor Peer Group Support

Deskripsi data skor hasil angket resilliance $\left(\mathrm{X}_{2}\right) \quad$ diperoleh perhitungan sebagai berikut: $\mathrm{N}=$ 100, Rentang Skor angket: $20-80$, Mean $=64,78$, Median $=65,50$, Modus $=66$, Standard Devias $(\mathrm{SD})=$ 5,539 , Skor tertinggi $=77$, dan, skor terendah $=45$. Mengingat data tersebut dilaporkan dengan grafik batang, maka perlu menghitung range (R) dan lebar kelas (i). Range (R) adalah selisih antara batas atas nyata skor tertinggi dan batas bawah nyata skor terendah $=77,5-44,5=$ 33. Ditentukan lebar kelas (i) $=5$, maka $\mathrm{R}$ dalam distribusi frekuensi bergolong $=(33+2): 5=7$.

Tabel 2. Distribusi Frekuensi resilliance $\left(\mathrm{X}_{2}\right)$

\begin{tabular}{|c|c|c|}
\hline Interval & Frekuensi (f) & Persentase \\
\hline $65-79$ & 52 & $52 \%$ \\
\hline $50-64$ & 48 & $48 \%$ \\
\hline $35-49$ & 0 & $0 \%$ \\
\hline $20-34$ & 0 & $0 \%$ \\
\hline Jumlah & 100 & $100 \%$ \\
\hline
\end{tabular}

\section{Gambar 3. Skor Resillence}

Deskripsi data skor hasil angket kemampuan coping adaptif (Y) diperoleh perhitungan sebagai berikut: $\mathrm{N}=100$, Rentang Skor angket: $20-80$, Mean $=66,97$, Median $=68$, Modus $=66$, Standard Devias $(\mathrm{SD})=5,264$, Skor tertinggi $=78$, dan, skor terendah $=50$. Mengingat data tersebut dilaporkan dengan grafik batang, maka perlu menghitung range (R) dan lebar kelas (i). Range (R) adalah selisih antara batas atas nyata skor tertinggi dan batas bawah nyata skor terendah $=78,5-49,5=29$. Ditentukan lebar kelas (i) $=5$, maka $\mathrm{R}$ dalam distribusi frekuensi bergolong $=(29$ $+1): 5=6$.

Tabel 3. Distribusi frekuensi kemampuan coping adaptif $\left(\mathrm{X}_{2}\right)$

\begin{tabular}{|c|c|c|}
\hline Interval & Frekuensi (f) & Persentase \\
\hline $65-79$ & 54 & $54 \%$ \\
\hline $50-64$ & 46 & $46 \%$ \\
\hline $35-49$ & 0 & $0 \%$ \\
\hline $20-34$ & 0 & $0 \%$ \\
\hline Jumlah & 100 & $100 \%$ \\
\hline
\end{tabular}


Bentuk grafik batang distribusi frekuensi kemampuan coping adaptif adalah sebagai berikut

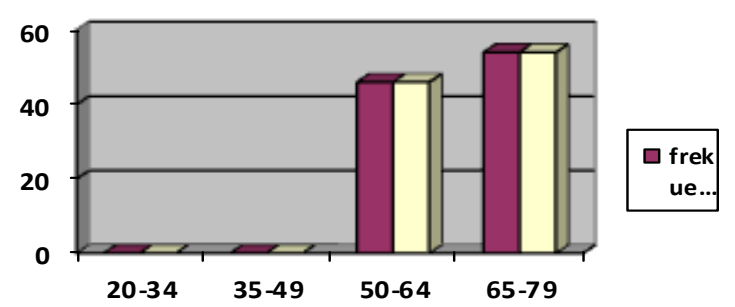

Gambar 3. Skor Kemampuan Coping Adaptif

\section{Hasil Analisis Data}

Hasil penelitian diperoleh dengan cara menganalisis data $X_{1}$, $\mathrm{X}_{2}$ dan $\mathrm{Y}$, sehingga diperlukan table persiapan untuk menghitung pengaruh Peer Group Support $\left(\mathrm{X}_{1}\right)$ dan Resillence $\left(\mathrm{X}_{2}\right)$ terhadap Kemampuan Coping Adaptif (Y).

Bertolak dari hasil perhitungan dengan program exel, selanjutnya digunakan sebagai dasar membuat analisis data sebagai berikut: Analisis Data Pengaruh Peer Group $\mathrm{X}_{1} \quad$ Terhadap $\mathrm{Y}$ dengan menggunakan rumus korelasi Product Moment hasilnya menunjukan skor 0,851. Analisis data pengaruh $\mathrm{X}_{2}$ terhadap $\mathrm{Y}$ menunjukan skor sebesar 0,915. Sedangkan analisis data pengaruh $\mathrm{X}_{1}$ dan $\mathrm{X}_{2}$ terhadap $\mathrm{Y}$ dimulai dengan mengubah menjadi skor deviasi, maka hasil perhitungannya dapat diketahui sebagai berikut 2.642,34. Persamaan simultan untuk mencari $a_{1}$ dan $a_{2}$ adalah sebagai berikut:

(1) $\sum \mathrm{x}_{1} \mathrm{y}=\mathrm{a}_{1} \sum \mathrm{x}_{1}^{2}+\mathrm{a}_{2} \sum \mathrm{x}_{1} \mathrm{x}_{2}$

(2) $\sum x_{2} y=a_{1} \sum x_{1} x_{2}+a_{2} \sum x_{2}^{2}$

Koefisien korelasi antara kriterium $\mathrm{Y}$ dengan prediktor $\mathrm{x}_{1}$ dan prediktor $\mathrm{x}_{2}$ dihitung dengan rumus sebagai berikut:

$\operatorname{Ry}(1,2)=\sqrt{\frac{\mathrm{a}_{1} \sum \mathrm{x}_{1} \mathrm{y}+\mathrm{a}_{2} \sum \mathrm{x}_{2} \mathrm{y}}{-\mathrm{N \textrm {y } ^ { 2 }}}}$

(Sumarwoto, 2017: 77).

Hasil perhitungan $\operatorname{Ry}(1,2)$ menunjukan hasil 0,8453 (dikuadratkan untuk kepentingan analisis regresi) besarnya $R^{2}=0,715$. Untuk mengetahui apakah hasil $\operatorname{Ry}(1,2)=0,8453$ itu signifikan atau tidak, maka perlu dihitung dengan menggunakan rumus F-regresi sebagai berikut:

$$
\text { Freg }=\frac{\mathrm{R}^{2}(\mathrm{~N}-\mathrm{m}-1)}{\mathrm{m}\left(1-\mathrm{R}^{2}\right) \quad \text { (Sutrisno }}
$$

Hadi, 1990: 26)

Hasil perhitungan dari rumus diatas menunjukan skor sebesar 121,68. Harga F-hitung dengan d.b $=(\mathrm{m}$ melawan $\mathrm{N}-\mathrm{m}-1)=$ atau 2 melawan $97=3,09 / \mathrm{TS}=5 \%$. Jadi sangat signifikan atas dasar taraf signifikansi sebesar $5 \%$.

\section{PEMBAHASAN}

Berdasarkan analisis data diketahui bahwa ada pengaruh peer 
group support dan resiliensi terhadap kemampuan coping adaptif pada siswa kelas SMA. Secara teoritis peer group support merupakan suatu dukungan sosial yang menggabungkan berbagai infomasi, penilaian (feedback) dan emosional (Ekasari, 2013). Peer group support merupakan bantuan dengan rasa hormat, penuh tanggung jawab, dan kesepakatan bersama, dengan melalui dukungan persahabatan, empati, saling berbagi, dan saling memberi dan menerima. Hasil perhitungan sumbangan efektif, peer group support berpengaruh sebesar $72,37 \%$ terhadap kemampuan coping adaptif..

Sedangkan peer group support yang baik akan berlangsung secara maksimal apabila didukung oleh faktor resiliensi. Hakikat resiliensi sebagai adaptasi positif dalam menghadapi kesulitan. Hasil perhitungan sumbangan efektif, resiliensi berpengaruh sebesar $65,22 \%$ terhadap kemampuan coping adaptif.

Hasil penelitian ini menyebutkan ada pengaruh yang signiifikan antara peer group support dan resiliensi terhadap kemampuan coping adaptif. Hal ini dikarenakan hasil temuan penelitian menunjukkan bahwa nilai korelasi menunjukkan $\mathrm{R}_{\text {hitung }}$ lebih besar dari $\mathrm{R}_{\text {tabel }}$ sehingga ada hubungan antara peer group support dan resiliensi terhadap kemampuan coping adaptif siswa kelas X. Kemampuan coping adaptif diartikan sebagai kesanggupan atau kemampuan seseorang (individu) dalam proses aktivitas kognitif yang disertai dengan aktivitas perilaku dalam pemilihan cara untuk menyesuaikan diri secara tepat terhadap situasi hidup yang menekan, yang timbul dari hubungan individu dengan lingkungan (Saptoto, 2010)". Pernyataan tersebut pada prinsipnya memberi kejelasan bahwa dalam menjalankan kehidupannya seseorang dituntut untuk bersikap terhadap dirinya sendiri dan lingkungan dimana dirinya hidup dan berada. Adanya pengaruh yang signifikan peer group support dan resiliensi terhadap kemampuan coping adaptif siswa ini juga didukung dengan hasil analisis data yang menunjukkan nilai $F_{\text {hitung }}$ lebih besar dari $F_{\text {tabel. }}$ Hasil dari sumbangan efektif peer group support dan resiliensi terhadap kemampuan coping adaptif sebesar $7,17 \%$.

\section{SIMPULAN}

Hasil analisis data pengaruh peer group support $\left(\mathrm{X}_{1}\right)$ terhadap kemampuan coping adaptif (Y) menunjukkan bahwa harga $\mathrm{r}_{\mathrm{x} 1 \mathrm{y}}=$ 0,851 . Harga r-tabel, dengan $\mathrm{N}=100$ $=0,195 / \mathrm{TS}=5 \%$. Jadi $\mathrm{r}$-hitung $>\mathrm{r}$ tabel (signifikan). Oleh sebab itu dinyatakan ada pengaruh peer group support terhadap kemampuan coping adaptif siswa SMA.

Hasil analisis data pengaruh resillience $\quad\left(\mathrm{X}_{2}\right)$ terhadap 
kemampuan coping adaptif (Y) menunjukkan bahwa harga $\mathrm{r}_{\mathrm{x} 2 \mathrm{y}}=$ 0,915 . Harga r-tabel, dengan $\mathrm{N}=100$ $=0,195 / \mathrm{TS}=5 \%$. Jadi $\mathrm{r}$-hitung $>\mathrm{r}$ tabel (signifikan). Oleh sebab itu dinyatakan ada pengaruh resillience terhadap kemampuan coping adaptif pada siswa SMA.

Hasil analisis data pengaruh peer group support $\left(\mathrm{X}_{1}\right)$ dan resillience $\left(\mathrm{X}_{2}\right)$ terhadap kemampuan coping adaptif (Y) menunjukkan bahwa harga F-regresi (F-hitung) = 121,68. Harga F-tabel, dengan d.b = m lawan $(\mathrm{N}-\mathrm{m}-1)=3,09$. Jadi $\mathrm{F}$ hitung > F-tabel (signifikan). Oleh sebab itu dinyatakan ada pengaruh peer group support dan resillience terhadap kemampuan coping adaptif pada siswa SMA.

\section{DAFTAR PUSTAKA}

Bartram, David \& Dianne, Gardner. Coping with stress. In Practice, 30 228-231

Ekasari, Agustin dan Zesi Andriyani. (2013). Pengaruh Peer Group Support dan self-esteem terhadap resillence. Proyeksi (online). Vol. 6 No (1). Di unduh pada tanggal 8 April 2017 pukul 11.50 WIB. https://www.google.com.sg/sea rch? client=msandroidoppo\&ei $=3 \mathrm{SkoWYmn}$ MouBvwSB8rCACw\&q=skrip si+peer + group + support\&oq $=$ skripsi + p eer+group+support\&gs_l=mob ile-gws-
Hadi, Sutrisno. (1990). Analisis Regresi. Yogyakarta: Andi Offset

Saptoto, Ridwan. (2010). Hubungan Kecerdasan Emosi dengan Kemampuan Coping Adaptif. Proyeksi Online. Vol. 36 No (1). Di unduh pada tanggal 23 April 2017 pukul 18.50 WIB.https://www.google.com. $\mathrm{sg} /$ search?client=ms-androidoppo\&ei=itMqWcLNJImMvQ Te9K6YAg\&q=teori+peer+gro up+pdf\&oq=skripsi+peer+grou p+support\&gs_l=mobile

Sangaji dan Sopiah. (2010). Metedologi Penelitian. Jakarta: PT Raja Grafindo Persada.

Sugiyono. (2015). Metedologi Penelitian dan pengembangan. Bandung: Alfabeta

Sumarwoto. D.S (2017). Statitistik Inferensial. Diktat Kuliah. Madiun: Universitas PGRI Madiun

Thompson, Renee J., dkk. (2010). Maladaptive coping, adaptive coping, and depressive symptoms: Variations across age and depressive state. Behaviour Research and Therapy journal 48 (2010) 459-466 homepage: www.elsevier.com/locate/brat

Winkel, WS. \& Hastuti, MM. Sri. (2007). Bimbingan dan Konseling di Institusi Pendidikan (Revisi). Jakarta: Media Abadi

Winarsih, Rumi. (2006). Kurikulum Kesenian Pasca Gempa SD/MI Di Daerah Istimewa Yogyakarta. Skripsi FBS Universitas Nergeri Yogyakarta 
$1 \quad$ Jurnal Ilmiah Counsellia, Volume 8 No.1, Mei 2018|27-36 